\title{
Desde el recuerdo y la memoria: una recuperación del quehacer de profesoras en la escuela primaria
}

\author{
From remembrance and memory: A recovery \\ of the work of female teachers in primary schools
}

Cirila Cervera Delgado • Mireya Martí Reyes

\begin{abstract}
RESUMEN
Con el presente artículo pretendemos caracterizar la labor de las maestras en el ciclo educativo de la escuela primaria, tal como permanece en la memoria de quienes fueron sus alumnas/os en un periodo aproximado de I974 a 1993. Se deriva del proyecto "Historia social e historias de vida. Educación de mujeres en Guanajuato", cuyo objetivo es contribuir a la visibilización de las mujeres a partir de su incursión en la escuela y, si es el caso, en diferentes carreras en las que abrieron camino, como el magisterio; planteamos como supuesto que ser maestras fue una elección profesional y de vida para esas mujeres. La investigación se ha nutrido con los relatos de profesoras/es, recuerdos de sus docentes de educación primaria. Las narraciones se agrupan en torno a dos momentos de la historia de la educación reciente: a partir de 1974 y de 1993, apenas implementadas la Tecnología Educativa y el Acuerdo Nacional para la Modernización de la Educación Básica, respectivamente. Elegimos que las/los relatores sean profesoras/es en activo, porque el ejercicio de recordación y recuperación de la memoria acerca de sus profesoras adquiere un significado que no tendría si lo hacemos con otra población, porque aspiramos a conocer si las prácticas didáctico-pedagógicas y educativas en el horizonte temporal entre reformas surtieron efecto en la vida diaria de las aulas o si, por el contrario, los usos y costumbres prevalecieron sobre las propuestas de la política educativa, siguiendo conceptos básicos de la historia cultural. Los hallazgos obtenidos mediante un trabajo inductivo de historia oral indican que las enseñanzas de las profesoras se centran en los contenidos programáticos, pero no se constriñen a este subconjunto: su labor educativa transcurre en determinados espacios culturales en donde su tarea trasciende hasta moldear los destinos de sus alumnas/os.
\end{abstract}

Palabras clave: Educación primaria, feminización del magisterio, historia cultural, historia oral, reforma educativa.

\section{ABSTRACT}

With this article we aim to characterize the work of female teachers during the educational cycle of primary school, as it remains in the memory of who their students were in an approximate period from I974 to I993. It is derived from the project "Social history and life stories. Education of women in Guanajuato", which objective is to contribute to the visibility of women, starting from their foray into school and, if it is the case, in different careers in which they opened the way, such as teaching. We assume that being a teacher was both a professional and a life choice for these women. The research is nourished with the stories of teachers, memories of their primary school teachers. The narrations are grouped around two moments in the history of recent education: from 1974 and from 1993, the Educational Technology and the National Agreement for the Modernization of Basic Education, as soon as they were put into effect, respectively. We chose that the rapporteurs be active teachers, because the exercise of remembering and recovering memory about their teachers acquires a meaning that it would not have if we did it with a different population. We aspire to know whether didactic-pedagogical and educational practices in the time horizon between reforms had an effect on the daily life inside the classrooms, or if, on the contrary, the uses and customs prevailed over the proposals of educational policy, following basic concepts of cultural history. The findings indicate that the teachers' teachings focus on the programmatic content, but are not limited to this subset: their educational work takes place in certain cultural spaces where their task transcends to shape the destinies of their students.

Keywords: Primary education, feminization of the teaching profession, cultural history, oral history, educational reform.

Cirila Cervera Delgado. Universidad de Guanajuato, México. Profesora de Tiempo Completo Titular A en el Departamento de Educación. Es doctora en Historia por la Universidad Autónoma de Zacatecas. Entre sus publicaciones recientes se encuentran "Huellas académicas. El Departamento de Educación a medio siglo: trayectoria y desafíos" (2019) y "Educación, historia, cultura. Re-visiones desde la multidisciplina” (2019). Cuenta con los reconocimientos al perfil Prodep y del Sistema Nacional de Investigadores, Nivel I. Temas de interés: historia de la educación de mujeres y formación y currículo. Correo electrónico: cirycervera@ugto.mx. ID: https://orcid.org/0000-000I-8036-838X.

Mireya Martí Reyes. Universidad de Guanajuato, México. Doctora en Ciencias sobre Arte por el Instituto Superior de Arte de Cuba. Actualmente es directora del Departamento de Educación de la Universidad de Guanajuato y responsable del Cuerpo Académico Consolidado "Educación en la Cultura, la Historia y el Arte". Entre sus publicaciones recientes se encuentran "Paisajes musicales. Investigación del origen y desarrollo de la música popular de banda de viento en el estado de Guanajuato" (2018) y "Educación, historia, cultura. Re-visiones desde la multidisciplina” (2019). Correo electrónico: mireya@ ugto.mx. ID: https://orcid.org/0000-000I-8959-754I. 


\section{Introducción}

Todo lo bumano tiene una bistoria,

simplemente necesitamos descubrir cómo escribirla.

Peter Burke

El presente artículo es una aproximación a la caracterización de las tareas de maestras de educación primaria que ubicamos en un horizonte temporal alrededor de I974 a I993, un periodo entre reformas educativas derivadas de la política a nivel federal: la Tecnología Educativa y el Acuerdo Nacional para la Modernización de la Educación Básica.

Recuperamos el quehacer de las maestras tal como permanece en la memoria de quienes fueron sus alumnas/os (todos docentes en activo al momento de hacer las entrevistas) a través de un ejercicio de recordación traducido en relatos breves sobre sus profesoras. El trabajo tiene su origen en el proyecto de investigación "Historia social e historias de vida. Educación de mujeres en Guanajuato", cuyo objetivo principal es contribuir a la visibilización de las mujeres en la educación, a partir de su incursión en la escuela (desde la básica hasta la superior, si es el caso) y, cuando aplica, en el desempeño de diferentes profesiones, en las cuales tuvieron que abrir camino. Partimos del supuesto de que las mujeres han tenido que recorrer y sortear sendas en condiciones desiguales que se les imponen por cuestiones de género y que, en reiteradas ocasiones, han optado por carreras feminizadas, entre las que sobresale el magisterio como una elección profesional y de vida.

Cronológicamente, los relatos se concentran en dos momentos indicativos de la historia de la educación reciente en nuestro país, a partir de I974-I975 y I992-I993, es decir, cuando apenas se implementaban los modelos curriculares de la Tecnología Educativa y el Acuerdo Nacional para la Modernización de la Educación Básica, respectivamente. De este modo obtuvimos una primera y aproximada lectura a la profesión de educar de aquellas maestras que no registra la historia oficial, pero que igual construyen cultura en espacios culturales particulares que constituyen el aula y la escuela, mediados por áreas más amplias alejadas, y acaso ajenas, como es el ámbito de la política educativa.

\section{Antecedentes}

La historia de la educación de las mujeres registra antecedentes con estudios de carácter psicológico, antropológico, sociológico, histórico y de género. Aquí solo hacemos mención de las aportaciones más directamente relacionados con este trabajo. La tesis de García (20I I) "Mujeres, maestras y diversidad. Historias de vida" sitúa su objeto de estudio en Oaxaca, que, en cuanto al nivel de escolarización de las mujeres, retrata un escenario por demás preocupante aún en el presente. En su ponencia "La estela del cometa: la historia de las mujeres en la educación”, Hinojosa (2009, p. I) reitera el estado que prevalece en el campo: 
Dentro del debate de la historiografía de la educación, aparece apenas tímidamente, la historia de las mujeres. Por lo general, este giro de la historiografía es invisibilizado o ignorado porque el centro de atención de esta producción se centra en la vida pública, ámbito dominado completamente por los hombres.

Por su parte, Galván y López (2008), entre otras connotadas investigadoras de la historia de la educación, concluyen que el magisterio les era un campo permitido a las mujeres porque se consideraba como una extensión del ser femenino, con los atributos de la ternura, la delicadeza, el cuidado... ser maestra era una continuación del hecho natural de ser madre. Bertely y Alfonseca (2008) refuerzan esta tesis de que el magisterio, como la enfermería, era asequible a las mujeres por ser considerada una profesión de asistencia, no de inteligencia; los autores coinciden en que la formación en las escuelas Normales representó una oportunidad factible para las mujeres y el ejercicio del magisterio constituyó parte de sus historias profesional y de vida. La obra de González Las maestras en México. Re-cuento de una bistoria (2007) es una síntesis del devenir de la profesión docente. Finalmente, un aporte de carácter analítico lo ofrecen Montero y Esquivel (2000) en el artículo "La mujer mexicana y su desarrollo educativo".

En general, las investigaciones sobre maestras en México van a coincidir en que el magisterio les fue accesible y socialmente bien visto por considerarlo propio para ellas al ir "de acuerdo con su naturaleza"; que ingresar a la escuela Normal era una de las pocas opciones que tenían las mujeres de hacer una carrera y de ejercer una profesión.

Con estos antecedentes, intentamos hacer una lectura de las realidades más particulares de la cotidianidad del quehacer de las profesoras de primaria, que, como mostraremos, trasciende la dimensión técnica de la enseñanza para incidir en los aprendizajes significativos para la vida de sus alumnos, y anticipamos que la historia del magisterio debe mucho a la profesión de las maestras. Con este ejercicio inductivo intentamos recuperar la obra de algunas mujeres educadoras a través de la recordación que hacen sus pupilas/os que siguieron sus pasos, convirtiéndose, en su momento, en profesoras/es de educación primaria.

\section{México entre reformas: la Tecnología Educativa y el Acuerdo Nacional para la Modernización de la Educación Básica}

En este breve panorama de la historia de México nos referimos a los sexenios presidenciales de Luis Echeverría Álvarez (1970-1976) y Carlos Salinas de Gortari (I9881994) de manera particular, hacemos una breve descripción de las características de la época de la Tecnología Educativa ${ }^{\mathrm{I}}$ y del Acuerdo Nacional para la Modernización de la Educación Básica (ANMEB).
I Para la caracterización de la reforma educativa en este periodo puede consultarse el trabajo del doctor Ángel Díaz Barriga, "La evolución del discurso curricular en México (19701982)”. Asimismo, el sentido que la reforma proponía para la educación básica quedó plasmado en el documento de la Secretaría de Educación Pública (I974), justamente llamado Educación media básica. Resoluciones de Chetumal. Plan de estudios. Programas generales de estudio. 
2 Producto de este enfoque es que, por ejemplo, la historia, geografía y educación cívica se conjugaron en el estudio de las Ciencias Sociales.

3 Inclusive desde la entrada en vigor de la Tecnología Educativa, en la primera mitad de la década de los setenta; sin embargo, la enseñanza de la lectura y la escritura se continuó haciendo con diversos métodos como el silábico y el onomatopéyico.

4 De acuerdo con el principio skineariano de que aprendizaje es un cambio de conducta. En consecuencia, se impuso una evaluación (medición) de los resultados de aprendizaje por objetivos, con el requisito de ser enunciados precisos y en términos medibles.
Como presidente de la República, Echeverría puso en marcha una Comisión Coordinadora de la Reforma Educativa para diversificar los servicios del área, aumentar el número de escuelas y modificar los planes de estudio, poniéndolos ad boc al México de ese entonces. La reforma de este periodo se reflejó en la publicación de la Ley Federal de Educación, en 1973 y, en lo pedagógico, estuvo animada por la llegada a la educación básica de la racionalidad técnica del currículum, que concretamente se tradujo en un plan de estudios organizado por materias y con un enfoque de aprendizaje global, ${ }^{2}$ muy notorio en los planes de estudio de la primaria. A partir del conocimiento como un todo interrelacionado cobraron auge los métodos de lecto-escritura basados en este concepto, como el muy recordado "Método global de análisis estructural" con el que debían enseñar los profesores durante el lapso aproximado de 1975 a $1994 .{ }^{3}$

Otro distintivo de esta reforma, en fiel apego a los preceptos del conductismo, es que la enseñanza cobró sentido en tanto la evaluación, basada en objetivos, daba resultados de aprendizaje medibles en los alumnos mediante el cambio de conducta. ${ }^{4}$ Se confiaba en que la planificación educativa racional (en los niveles macro y micro) fuera la panacea para todos los problemas de índole educativa. Esta reforma exigió un cambio en el programa de estudios, en los libros para el maestro y para los alumnos; en sus contenidos, imágenes y modo de hacer la enseñanza. A este hecho, vigente hasta 1992 -con modificaciones secundarias intermedias- le acompañó un crecimiento histórico, y muy significativo en esas décadas, en la matrícula de primaria, secundaria y preescolar. De modo particular, la primaria alcanzó una cobertura universal.

Durante el sexenio presidencial de Carlos Salinas de Gortari se firmó el Acuerdo Nacional para la Modernización de la Educación Básica (ANMEB), en vigencia hasta entrada la década actual y, por lógica, con un traslape por demás notorio con el modelo educativo vigente al menos hasta el año 20I8. De los cinco componentes en que se estructuraba al Acuerdo, nos interesa rescatar el que implicó una reforma curricular y pedagógica para la educación básica obligatoria, con un impacto en el hacer en el aula. Los programas de estudio cambiaron, resaltando la enseñanza de contenidos como la formación cívica y ética, la historia y la geografía, y anunciando que el enfoque sería el aprendizaje significativo, organizado en conceptos básicos. Los libros de texto también se modificaron paulatinamente: el material fue mucho más atractivo para los estudiantes, en papel blanco, con un mayor porcentaje de ilustraciones a color y con cubiertas llamativas. Cabe destacar que esta reforma coincidió con la firma del Tratado de Libre Comercio de México con los Estados Unidos y Canadá.

Entre ambos puntos, es pertinente anotar que a los estudios de Normal se les había adjudicado el estatus de educación superior en 1984, por decreto del entonces presidente Miguel de la Madrid Hurtado. También señalamiento aparte merece la creación de la Universidad Pedagógica Nacional en 1978, que inicialmente tuvo el objetivo de 
profesionalizar al magisterio, otorgando títulos de licenciatura a los profesores que la cursaran, después de la Normal.

Consideramos importante señalar estos hitos, pues, como describiremos enseguida, las profesoras que recordamos se agrupan en uno u otro momento históricos; asimismo, la mayoría solo tenía estudios de Normal y el resto, muy pocas, ya eran egresadas de la licenciatura en Educación, bien sea de la Universidad Pedagógica Nacional o de alguna escuela Normal Superior.

\section{Enfoque metodológico}

Con la elección de un enfoque metodológico cualitativo buscamos ceder la voz, en tercera persona, al magisterio. Dado que los narradores son docentes actualmente en servicio, pero que se refieren a sus profesoras, resulta necesario precisar esta perspectiva, más en lo que corresponde a los sujetos (las profesoras que son recordadas en los relatos y las y los relatores mismos).

Hemos adaptado el relato biográfico único en tercera persona (Pujadas, 2000, pp. I35-I44), esto es, la recuperación de episodios de vida en el aula de profesoras a través del ejercicio de recordación y narrativa de quienes fueron sus alumnas/os y hoy son profesoras/es. Los testimonios debían cumplir, de alguna manera, con el requisito de ser "representativos" del colectivo magisterial al que aspiramos a caracterizar, sin obviar los sesgos propios de la subjetividad individual, "a pesar de los rasgos de irreductible especificidad que cualquier estudio de caso muestra” (Pujadas, 2000, p. I4I).

Esto es, los testimonios debían referirse a profesoras de primaria (cualquier grado) y ser relatados por profesoras o profesores en servicio. Además, las y los narradores debían contar con formación docente. Con cada uno de ellos desarrollamos una entrevista "de orientación biográfica” (Pujadas, 2000, p. I39) a partir de un solo tema detonador, a saber: "Describa a la profesora que le haya dado clases en primaria que más recuerde." Adicionalmente se pidió: a) los datos de la escuela, el grado y el ciclo lectivo en que se ubicaba su respuesta, y b) empleo actual del/la entrevistado/a.

Recabamos 20 relatos válidos. ${ }^{5}$ El tratamiento se hizo con base en dos elementos de la recordación:

I. Enseñanzas de carácter técnico, esto es, de contenidos programáticos (lectoescritura, matemáticas, conceptos de ciencias naturales, civismo, etc.).

2. Enseñanzas de vida, donde agrupamos cuestiones o temas más concerniente al ámbito de valores, actitudes, vocación (paciencia, amor pedagógico, generosidad, etc.).

A fin de dar cuenta del hacer de las maestras en aquellos ayeres, retomamos fragmentos narrativos que aluden a las enseñanzas. Se identifica al narrador con su nombre entre corchetes. En síntesis, como indica Pujadas: "Sin llegar al extremo de pretender
5 La selección de la muestra de 22 docentes fue por conveniencia y cercanía, no es una muestra probabilística. Desechamos un relato por la pobreza del texto y otro porque no contenía datos para identificar la escuela ni las fechas a las que se refería. 
realizar una transcripción fonética, sí que podemos producir transcripciones que reflejen perfectamente el estilo personal de cada informante" (2000, p. I39), las palabras que ilustren el quehacer de sus profesoras y que nos permitan hacer una descripción de la historia del magisterio de los horizontes temporales estudiados.

\section{Resultados: maestras de ayer en voces de hoy}

Las tendencias en la educación (con su concreción en prácticas didáctico-pedagógicas) como la Tecnología Educativa y al Acuerdo Nacional para la Modernización de la Educación Básica demandaban la aplicación de enseñanza y aprendizaje distintos entre sí, por tanto, procederes diferentes del profesorado en las aulas. Eso, sin duda, permanece en la memoria de los entrevistados. Empero, más allá de los marcos generales, la historia oral, mediante el material biográfico, "ayuda a ahuyentar el fantasma de la tipificación de los sujetos como representativos o característicos de un orden sociocultural determinado, mediante la introducción de los sesgos subjetivos y personales, que permiten evidenciar las diferentes posiciones, sensibilidades y experiencias individuales" (Pujadas, 2000, p. I30), esto es, la construcción de una cultura propia y específica, según la historia cultural. Con estos referentes, nos percatamos, por un lado, de la traducción que en su momento hizo el profesorado de los lineamientos de las reformas educativas, y por el otro, la interpretación que hacen de esos procederes las/los profesores entrevistados.

Pues bien, en la mayoría de los relatos es notoria la tendencia hacia aquellos elementos que atañen a la dimensión personal de las profesoras y de los entrevistados (actitudes, valores, ejemplos de vida, etc.). Como algunos de los más ilustrativos reproducimos los siguientes:

La maestra de quinto grado [1979-I980; Carmen Graciela, de la Escuela Primaria Urbana No. 5,

"Independencia”], fue la primera persona de quien recibí una gran confianza y mucho estímulo. Yo sé que fui una excelente alumna, pero muy poca gente me lo decía y me animaba en esos años... Ella me regaló un fantástico libro: Mujercitas. Con él, me dio el mensaje de que siguiera leyendo y escribiendo... de que podría llegar a ser una gran mujercita [Ana Tere, profesora de bachillerato].

Yo era muy tímida, pero la maestra Yara [tercero y sexto grado en la Escuela "Niños Héroes", de León, Gto., I979-I980 y I982-I983] me impulsaba para que leyera al frente y perdiera el miedo. Me enseñó a sacar la voz, a pararme bien, a ver al público a la vez que leía el libro [Bety, profesora de primaria].

Mi maestra Conchita me enseñó a ser muy limpio. Nos revisaba la ropa, el cabello, las uñas... y sabía, por el olor, cuando no nos habíamos bañado [...] eso lo hacía a diario, era parte de las tareas que le debíamos mostrar. Nuestro salón siempre estaba ordenado, los materiales en el sitio que les correspondía. Y todo nos lo decía de un modo muy amable y cariñoso [Rafa, maestro de primaria; en referencia a su profesora de sexto grado en la Escuela "Xicoténcatl”, I982-I983]. 
Los testimonios van de la recordación de un aspecto en apariencia muy particular hasta los que refieren la influencia de esas profesoras en su vocación hacia la docencia, su ocupación actual. Fragmentos de otros relatos se distinguen por corresponderse con enseñanzas de determinado contenido programático. Podemos citar los siguientes:

No me gustaba que me dejara castigada... pero no me aprendía las tablas [de multiplicar] y eso significaba que estaríamos hasta la noche [el turno era vespertino], con velas para alumbrarnos... era repasar de memoria en voz alta, todos con la maestra Rosy [profesora de segundo grado en la Escuela Primaria "Henry Ford", I978-1979]. Y luego a hacer planas y planas... y te volvía a preguntar. Eso no era agradable, pero entrené la memoria. Luego ya me aprendía todo de memoria muy fácil [Lucy, profesora de primaria].

Los mapas grandes que estaban en el salón eran muy bonitos... la maestra los utilizaba muy seguido y nos decía que era importante saber en dónde estábamos. Pero no solo identificábamos el país y el estado, sino las cadenas montañosas, los ríos, los mares y océanos. Llevaba objetos: aretes, un florero, un llavero, y nos decía de qué lugar eran, porque ella había ido a esos lugares [...] muy bien que ella completaba el material con el que ella hacía y con lo que nos decía. Esa sí era geografía [Leonardo, profesor de primaria, en referencia a su profesora de $4^{\circ}$ grado en la Escuela Primaria "Hermanos Aldama”, I992-I993].

Para enseñarnos a contar nos dio un anzuelo y un pez de cartón [como molde] para que con él [en casa] nos cortaran muchos pececitos de periódico. Ya en el salón, jugábamos a los pescadores y nos daba gusanitos de gomitas de dulce, nos subíamos en las mesitas, era un mobiliario, salones y escuela muy modernos, y jugando aprendíamos a contar, sumar y restar [Laura, profesora de Telesecundaria; maestra Antonia, Toñita, Escuela “General Vicente Villada”, Toluca, Estado de México, primer grado, ciclo escolar I977-1978].

A la maestra le gustaban mucho las matemáticas. Nos enseñaba con canciones y juegos, muchos juegos; con material que ella elaboraba de cartón o cartulina de colores. Nos pedía corcholatas o palitos de paleta. En el salón éramos como sesenta alumnos [...] varios reprobaban, pero no era por la maestra. Ella era muy buena para enseñar [Mónica, profesora de escuela Normal, en relación con la maestra Graciela, primer grado, Escuela Primaria Urbana No. 5, "Independencia”, León, Gto., ciclo lectivo I976-I977].

Los fragmentos anteriores testimonian el quehacer de las profesoras, en gran medida concentrado en la enseñanza de los contenidos de un programa oficial. Sin embargo, a través de esos contenidos se vislumbra la trascendencia del ser de las profesoras, en una especie de currículum oculto: las enseñanzas no se constriñen a un tema del libro, sino que se toca a las esferas de las actitudes y valores, es decir, a la conformación de la personalidad de cada uno de los alumnos.

Asimismo, aunque la brevedad de este texto impide dar más muestras, el quehacer de las profesoras depende mucho más de sí mismas - de su creatividad, vocación, modo de entender la enseñanza- que de una reforma educativa. En el tiempo de la Tecnología 
Educativa, si bien es cierto que se dieron prácticas de memorización mecánica, también hubo profesoras que acudían a un enfoque más lúdico, con el que pretendían otorgar un sentido más comprensivo a lo que enseñaban.

Como docentes que son, las y los relatores no dudan en asegurar que tienen influencia didáctica de sus profesoras y profesores de primaria; para algunos de ellos fue decisivo su ejemplo para elegir el magisterio como profesión. Aplican lo que aún está vigente, como dice Mónica: "Enseñar valores puede cambiar, pero no enseñan nada los valores por sí solos".

El ejercicio de recordación, con sus falencias, nos permite reconstruir una parte de la historia reciente de la educación, de la historia que se sucedía en las aulas de las escuelas primarias.

La mayoría de las y los entrevistados no había tenido oportunidad de evocar vivencias; darnos sus testimonios fue reencontrarse con un pasado que les aporta mucho para el presente, para su actuar cotidiano en los salones de clase. Rosy dijo: "Si no tuviera tanto quehacer, me pondría a hacer memoria y a escribir lo que viví en mi primaria; con ello y con lo que he vivido en estos más de 25 años de ser maestra, algo podría enseñar a los jóvenes que están en las Normales. Hasta mi Normal podría aprender algo”. Con este tipo de ejercicio tenemos la ganancia de poder "situar al propio sujeto en el contexto de los acontecimientos que nos está narrando y de dar entrada a recuerdos adormecidos u olvidados" (Pujadas, 2000, p. 138).

Por último, las narraciones de las y los profesores nos permiten recuperar pequeños fragmentos de la vida cotidiana que se desarrollaba en las aulas, más allá de lo que dictaban las reformas educativas, y nos acerca a una historia de las maestras. En los microrrelatos no hay pista alguna para inferir que los contenidos y los métodos en la escuela primaria se hayan modificado por un dictado de reforma o cambio. Por el contrario, como hasta hoy, el énfasis parece estar en contenidos básicos de lecto-escritura, operaciones básicas, geografía, historia. Tampoco tenemos elementos para afirmar que las profesoras que son recordadas ignoraran los cambios prescritos, solo atisbamos la presencia de una cultura escolar que mucho debe a la personalidad de las profesoras que, en colectivo, prefiguran una cultura propia del claustro y de los centros educativos.

\section{Conclusiones}

El transcurso de la investigación nos ha permitido darnos cuenta de que el proceder didáctico y los métodos y enfoques de los programas que sustentan las sucesivas reformas educativas se quedan al margen, acaso, de la actividad desarrollada por las profesoras, desplegada en un accionar que rebasa la didáctica para hacer educación, como una tarea de formar, más que de informar. 
Hemos presentado una aproximación al hacer docente de un grupo de profesoras de primaria en la historia de la educación reciente, a partir de un ejercicio de recordación de quienes fueron sus alumnos. Los relatos biográficos aportan datos objetivos, pero no obvios, sobre la traducción de la política educativa en las aulas. Las y los entrevistados no etiquetan a sus profesores bajo ningún rasgo de los planteamientos de las reformas, no hay menciones explícitas o implícitas que nos hagan suponer que están conscientes de que transcurrían. Pero sí podemos afirmar que más que las características de los programas oficiales predominan las enseñanzas básicas (lectura, escritura, formación cívica y personal), y que se hacen más al modo de ser de cada profesora que de un lineamiento general.

Finalmente, si bien es cierto que la memoria puede distorsionar lo que se vivió en realidad, nos importa, según nuestro propósito, recuperar esa parte subjetiva de vivir la educación: colocar la parte humana, individual y singular de esta, que también es historia.

\section{Referencias}

Bertely-Busquets, M., y Alfonseca Giner de los Ríos, J. B. (2008). Para una historiografía de la feminización de la enseñanza en México. Revista Mexicana de Investigación Educativa, I3(38), 98I-997. Recuperado de: http://www.scielo.org.mx/scielo. php?script=sci_arttext\&pid=SI 405-666620080003000I5\&lng=es\&tlng=es.

Burke, P. (2007). La historia cultural y sus vecinos. Conferencia dictada en el Instituto Mora. Alteridades, I7(33), I I I-I 17.

Chicangana Bayona, Y. A. (2009). Debates de la historia cultural, conversación con el profesor Peter Burke. Historia Crítica, (37), 18-25. Recuperado de: http://www.scielo.org.co/pdf/rhc/n37/n37a04.pdf.

de Garay, G. (1999). La entrevista de historia oral: ¿monólogo o conversación? Revista Electrónica de Investigación Educativa REDIE, I(I), 8I-89. Recuperado de: http://www.redalyc.org/articulo.oa?id=I550I 107.

Díaz Barriga, Á. (1985). La evolución del discurso curricular en México (1970-1982). Revista Latinoamericana de Estudios Educativos, I5(2), 67-79.

Galván, L. E., y López, O. (coords.) (2008). Entre imaginarios y utopías: bistorias de maestras. México: Programa Universitario de Estudios de Género-UNAM/Centro de Investigaciones y Estudios Superiores en Antropología Social/El Colegio de San Luis.

García, M. (20I I). Mujeres, maestras y diversidad. Historias de vida [Tesis de maestría]. Universidad Internacional de Andalucía, España.

González, R. M. (2007). Las maestras en México. Re-cuento de una bistoria. México: Universidad Pedagógica Nacional/Fundación para la Cultura del Maestro.

Hernández, A. (2019). Reseña de “¿Qué es la historia cultural?” de Peter Burke. Fronteras de la Historia, I5(2), 417-42I.

Hinojosa, R. (2009). La estela del cometa: la bistoria de las mujeres en la educación. Ponencia presentada en el X Congreso Nacional de Investigación Educativa. México: Consejo Mexicano de Investigación Educativa.

Montero, D., y Esquivel, L. (2000). La mujer mexicana y su desarrollo educativo: breve historia y perspectiva. Educación y Ciencia, 8(22), 5I-59.

Pujadas, J. (2000). El método biográfico y los géneros de la memoria. Revista de Antropología Social, (9), I27-I58.

Rodríguez, A. M., Luque, R. M., y Navas, A. M. (20I4). Usos y beneficios de la historia oral. ReiDoCrea, 3(24), 193-200. Recuperado de: https://dialnet.unirioja.es/servlet/articulo?codigo $=5386449$. 
Sancho Gil, J. (20I4). Historias de vida: el relato biográfico entre el autoconocimiento y dar cuenta de la vida social. Praxis educativa, I8(2), 24-33. Recuperado en: http://www.scielo.org.ar/scielo.php?script=sci_arttext\&pid=S0328$97022014000200003 \& \operatorname{lng}=$ es\&tlng=es.

Secretaría de Educación Pública (1974). Educación media básica. Resoluciones de Chetumal. Plan de estudios. Programas generales de estudios. México: SEP.

Secretaría de Educación Pública (1992). Acuerdo Nacional para la Modernización de la Educación Básica en México. México: SEP.

Serrano, H., y Serrano, C. (2006). Género y educación en México. Pharos, I3(2), 59-79.

Cervera Delgado, C. y Martí Reyes, M. (2019). Desde el recuerdo y la memoria: una recuperación del quehacer de profesoras en la escuela primaria. Anuario Mexicano de Historia de la Educación, l(2), 57-66. DOI: https://doi.org/I0.2935I/amhe.vIi2.246. 